\title{
Constructivist College English Learning Design Based on LAMS
}

\author{
Long Bin \\ Tianmu College \\ Zhejiang Agriculture and Forestry University \\ Lin’an, China \\ pennylonda@hotmail.com
}

\author{
Li Xueyan \\ School of Foreign Language \\ Changchun University of Technology \\ Changchun, China \\ 630707172@qq.com
}

\begin{abstract}
Constructivism emphasizes that learning does not mean knowledge passing down or knowledge cramming, rather learning is an interactive and constructive process involving constructing new knowledge based on previous knowledge and experience. And constructivist learning design theory evolves from basic theories to propose six relevant elements in learning design. The understanding and application of constructivist learning theory is believed to be crucial to change teachercentered classes and promote learning outcomes in real sense. Learning Activities Management System (LAMS) is software featuring engaging and motivating students by sequencing learning activities. This special function of LAMS is just in correspondence with what constructivists are calling for. This paper intends to under the guidance of constructivist learning design theory, propose a learning design for college English teaching by adopting LAMS.
\end{abstract}

Keywords-constructivist learning design, LAMS, college English learning design

\section{INTRODUCTION}

College English has long been put in a prominent place in the college curriculum system. However, decades of efforts and investment on college English reform do not seem to bring any changes to the teacher-centered English class. Students remain to be kind of containers to be poured with knowledge and in-class activities still highlight and follow teachers' wills. In addition, the evaluation of learning , which keeps intact compared with that of ten years ago, is made up of attendance, quiz, homework and final examination. The lack of evaluation on learning process is still a problem there. Development of information technology provides network platform-a new tool for both teaching and learning, but after years of practice, it turns out to be a tool for information searching, sharing and delivering, rather than true stimuli for teaching reform. Therefore what can be done to get the best out of students bringing in optimal learning outcomes is still a question awaiting its answers. The introduction of LAMS (learning activities management system, a software emphasizing sequencing of activities) guided by constructivism theory is very likely to give that question a way out in that LAMS highlights learning process rather than learning contents. In addition, we notice that constructivist learning design stresses learning environment in which knowledge is constructed. In view of LAMS' advantages over other learning software as well as essence of constructivist learning design theory, we presume that there might be a suitable joint between LAMS and the theory for College English teaching. Therefore aiming at transforming "teacher-centered" class into "student-centered" ,this paper intends to propose a constructivist learning design under the guidance of constructivist theory by using LAMS.

\section{RATIONALE}

Constructivism is a theory explaining how learning takes place. According to this theory, knowledge can not be learned, but acquired. Learning is not a process of pouring down or cramming knowledge into learners' head, rather it is an interactive, constructive and active process in one's own mind with new information, previous knowledge as well as experience involved. Constructivist learning believes that, true learning comes out (a) when knowledge is physically constructed by learners who are involved in active learning; (b) when knowledge is symbolically constructed by learners who are making their own representations of action; (c) when knowledge is socially constructed by learners who convey their meaning making to others;(d) when knowledge is theoretically constructed by learners who try to explain things they don't completely understand. [1]Based on this, according to George W. Gagnon, Jr. and Michelle Collay, the constructivist learning design lays a special emphasis on the following 6 elements: situation, groupings, bridge, questions, exhibit and reflections. To put it in details, situation means to put learners in a knowledge-learning environment which would provoke their interests for descriptions and analysis and this situation should involve what learners are expected to do and to learn; Groupings, on the one hand, is to divide learners into groups for collaborative learning, and one the other hand, is to group the materials that teacher is going to share with learners at teachers' will; Bridge is normally a question or a task which could help learner establish relationships between learners' previous knowledge or experience with new information; Questions might be involved in every element to elicit learners' response; Exhibit is make learners record and demonstrate what they learned. There might be a variety of ways to realize it: to draw a chart, to deliver a presentation, ect. Reflection is a process for learners to look back on what they have learned.

With a clear understanding of the constructivist learning design, we are moving into the step of designing college English learning. 


\section{COLLEGE ENGLISH LEARNING BASED ON LAMS}

Before the exact college English learning design is elaborated on, there should be a brief introduction to LAMS.LAMS was developed by a team with Professor Dalziel as leader in Macquarie University. LAMS features a range of learning processes which are realized by draging and droping a series of sequence of activities(noticeboard, chat and forum, share resouces, $\mathrm{Q}$ and $\mathrm{A}$, etc.) on the authoring interface. It is by organizing these sequence of activities that teachers can realize their ways of managing, operating and delivering their classes. What's more LAMS gives priority to learning process rahter than content and this makes it superior to other software. and the following learning design will be focused on how college English teachers adopt these sequence of activities in response to the six elements of constructivist learning design.

The following college English learning design will be revolved around the topic "what impacts does internet bring to our life". The prospective learning subjects are 30 college non-English major students in their second year study. The teaching objective covers two levels: (a) knowledge level: to widen students thinking by judging the pros and cons brought by internet; (b) language level: to appreciate the writing techniques employed in the text and to learn new words and useful expressions in order to help language output on this topic.This design is supposed to take 6periods.

In the first period, the teacher is going to lead students into the learning environment by giving the activities of "voting" and "chat and forum". Studens are required to vote on "what is the most wonderful inventions in the world?" and a few options mignt be supplied for reference, like electricity, printing, computers, cars, internet, etc. In addition to casting a vote, students are also required to share, discuss their reasons or even hold a debate with their classmates on forum. The aim of doing this is to arise students' interest and widen their thinking on this topic and finally help them to approach the expected topic.

After what is done in the first period, students surely get to know more about inventions changing their lives and in which aspects and how these changes take place. In the second period, the activities of "group" "share resources" , "notice board" and "notebook"will be adopted. With the activity of "group", the teacher can divide the class into 7 groups in the principle of better ones working with the poors according to their English proficiency. Then the first resource published by the teacher is hotly-discussed news at the following addresses:http://news.sina.com.cn/c/2012-095/083325247122.shtml,http://zhidao.baidu.com/question/43 4440987.html, etc. The resource provided by teacher are devided into two group with one covering potentia new words and expressions that students are going to use in the following tasks such discussion and composition and the other covering appealing update news, people or event close to students' life through which impacts of internet can be infered, for example Fetion, very popular among college students; the "smiling" deputy director and the most beautiful drive, hotly-discussed issues online. On notice board, the teacher would ask students to hold discussion about these people or event in the news and try to work out the question "what impacts does internet bring to our life". In this process, students are allowed to use the seaching engine to enrich their knowledge about the event or the people as well as to look up new words for further discussion. Their studying records will be kept on "notebook".

The third period might be a period for bridging what they already know to what they are going to know. In this period, students will be required to work collaboratively in group to list all the benefits and harms they could think out brought by the internet. To facilitate their work, the teacher is advised to share the digital work "Cyber-bullying”, and "Internet” with students. Meanwhile, potential useful words and expressions uploaded through the activity of "share resource" are certainly helpful to reinforce practice as wel as new knowledge-taken-in. They may be encouraged to hold a debate among groups. In this way, ideas will be enriched at maximum. To deepen and widen students' thinking on this topic, a qustion placed on "notice board" "what measures can be done to deal with the harms brought by internet" is suggested to follow. In this part, creative and practical measures are to be encouraged on forum.

The fourth period is still for knowledge bridging. This time students attention will be drawn to the writing strategies employed in the digital work of "Cyber-bullying" and "Internet". The teacher could lead students by posting questions on noticeboard like "Find out topic sentences in each paragraph", "What are the supporting evidences" , "what writing strategies are used" and "Find out words and phrases indicating coherence and cohesion". Then students work collaboratively in group to find out answers and hand in by "submit file”. After assessing students' performance, teachers might come up with following tasks whether to eleborate on writing strategies explanation or continue to do similar exericises. If results are not good enough to accept, teacher would focus on explanation. On the contrary, if results are satisfactory enough, teacher may move on with similar excercises to reinforce what has been learned.

The fifth period featuring "exhibit" is to adopt the activities of "Q\&A" and "submit files".Questions in this part will be closely linked to the understanding of the two texts and typical writing strategies used. Besides that, students will be asked to write a composition on the topic of "How do you view the internet?" , accordingly writing strategies practiced in last period should be employed,and finally hand in their composition through the activity of "submit files".

The sixth period is for reflections. To help studens look back on what they have learned. The activities of "multiple choices" and "Q\&A" will be employed to help reflections. By checking students' compositions and students' answers in "Q\&A" and their results in "multiple choices" plus the whole process of monitoring their involvement in 
discussing ,chatting and debating, teachers will easily assess students' learning performance and make relatively fair judgement on evaluation.

Taking into account six elements of constructivist learning design theory and typical features of LAMS, this learning design is bound to best bring out advantages of the theory as well as the software.Therefore there is no doubt that the optimal learning outcomes would turn out when this learning design is put into practice propery.

\section{APPLICATION AND ADAPTATION OF THIS LEARNING DESIGN}

One of the functions of LAMS is to save sequences for future use and there is no exception for this design. As for similar language teaching objectives and similar teaching context, this design is also applicable. It is generally acknowledged that we can improve learning considerably by making the conditions for optimal learning explicit, and then use this knowledge to design new events [2]. If so, to bring the best out of this learning design, adaptations depend on educational contexts. For instance, if 6 periods are required to be shortened concerning teaching plans for the whole semester, activities like "voting" can be deleted. Apart from that, if the teaching objective is laid more emphasis on "language output", teachers can add knowledge input in the form of documents with the help of "share resource" in the hope of saving learners' time for information searching, meanwhile, provide more opportunities for language practice by lengthening time for chatting and assigning writing tasks through the activities of "chat and forum" and " file submit". When it occurs to language teaching, this learning design is universally applicable. Concerning adaptation, LAMS is very flexible. However, what if applied in courses other than language? This question seems to be much more complicated. Considering traits of the courses, a few adaptations might work. For instance, if it is a course highlighting manipulation, say PHOTOSHOP, then activities for individual work should be emphasized. Anyway, the principle for adaptation is to provoke learners' optimal conditions by creating most suitable environment for knowledge constructing through which learners' potential could be best brought out.

\section{REVIEW OF CONSTRUCTIVIST COLLEGE LEARNING DESIGN}

With regard to the learning design as a whole, this design based on LAMS is well combined with constructivism. Firstly, a helpful and beneficial learning environment is established, successfully provoking learners' curiosity and interest to dig into the topic. Then collaborativities are given priority in the whole learning process in view of information searching, questions discussing and problems solving. Thirdly, a successful language class does not only mean language input, but also language output. Looking back on the whole learning process, language input starts from teachers' guidance and learners' voluntary efforts in following sequence of activities. When it comes to language output, "chat and forum" for discussing and exhanging information provides enough room and opportuities for practice and the process of language output happens in a completely relaxed and comfortable environment. Last but not least, task-based activities provide explicit goals for learners, otherwise they are easily lost. Based on the anaysis above, the constructivist college English learning design, if put it into practice by teachers, will be of great helps for teachers in realizing "stuent-centered" class and of great benefits for students in promoting learning outcomes. Even if a lot of advantages can be predicted, shortcomings should not be ignored. First, learning activities management does not mean to completely put learning at learners' hand, proper guidance from teachers is indispensable to a successful class, otherwise learners will be easily misled, meanwhile teachers full preparation for the whole activities design and proper reflections on sequence organizing are surely required. The second shortcoming lies in how to monitor learners, because monitor of LAMS could only tell whether learners have finished the tasks, but no more indications of whether their attentions are focused on the task rather than distracted. What if they are searching websites for entertainment. As far as I know, constant upgrade of LAMS has not come up with a method to solve the problem effectively. Hopefully, researchers of LAMS would notice the problem and advance proper solutions as soon as possible.

\section{CONCLUSION}

This paper takes constructivist learning design as theoretical framework proposing a practical college English learning design with using LAMS. LAMS with its unique feature of learning-process-orientation well perform and realize what constructivist learning theory is calling for. However, no learning design is perfect and so is theory and software. While arosing learners' interest in learning, the problem of easily directing learners's attention to irrelevant information is unavoidable. Except that, there are flaws on theories too, so constant perfection for learning design and constructism and cntant upgrade for learning management software are called for all the time. There is one principle for constant improvement: Creating designs for experiences that are motivating, enjoyable and productive for students and teachers alike [3]. Teaching serves learning and design is always learning-oriented

\section{REFERENCES}

[1] George W. Gagnon, Jr. and Michelle CollayG. “Constructivist Learning Design”

[2] Koper, R \& Tatersall, C. (2005), Learning Design: a handbook on modeling and delivering networked education and training, Springer. Retrieved from http://books.google.co.uk/books?id=MNQxDKbTpisC\&dq=what+is+ learning+design \&pg $=\mathrm{PP} 1 \&$ ots $=\mathrm{dlP} 0 \mathrm{osJPNg} \& \operatorname{sig}=6 \mathrm{cfACk}$ AC4JXh9 HSrDvIBck81Rg\&prev=http://www.google.co.uk/search\%3Fhl\%3Dz h-

CN\%26q\%3Dwhat\%2Bis\%2Blearning\%2Bdesign\&sa=X\&oi=print\& $\mathrm{ct}=$ result\&cd=1\#PPP1,M1 
[3] Manon,M.\&Bulk,D.,(n.d.) Phoebe: a pedagogical planner tool, Tall University of Oxford, http://wiki.cetis.ac.uk/uploads/8/84/PheobeCetisLiverpool.ppt\#256,1, Phoebe: a pedagogical planner tool, May, $29^{\text {th }}, 2007$.

[4] Gibbs, D. \& Philip, R., "Really Changing Teaching and Learning", Professional Educator, Vol. 4, No. 4. October 2005

[5] Dalziel, J. Implementing a Learning Design: The Learning Activity Management Systems (LAMS), In G.Crisp, D.Thiele, I.Scholten, S.Barkerand J.Baron (Eds), Interact, Integrate, Impact: Proceedings of the 20th Annual Conference of the Australasian Society for Computers in Learning in Tertiary Education. Adelaide, 7-10. December 2003
[6] Boud,D.,\& Prosser,M.. Key principles for high quality student learning in Higher Educatoin - from a learning perspective. Paper presented at a workshop held on April 27, 2001 for the AUTC funded project: Information and Communication Technologies and Their Role in Flexible Learning, Sydney, Australia.

[7] Harper, B.\&Oliver, R. "Reusable Learning Designs: information and communication technologies and their role in flexible learning", Presentation for the "AUTC Reusable Learning" Designs: opportunities and challenges" Conference, UTS, Sydney, December 2002.

[8] Lamssequence,

http://lamscommunity.org/lamscentral/sequence?seq\%5fid=426026. 